NASA's

Game Changing Technology Industry Day June 29-30, 2016



Advanced Manufacturing Technologies

John Fikes

NASA/MSFC 


\section{Advanced Manufacturing Technologies}

$>$ Advanced Manufacturing Technologies (AMT) is developing and maturing innovative and advanced manufacturing technologies that will enable more capable and lower-cost spacecraft, launch vehicles and infrastructure to enable exploration missions.

$>$ The technologies will utilize cutting edge materials and emerging capabilities including metallic processes, additive manufacturing, composites, and digital manufacturing.

$>$ The AMT project supports the National Manufacturing Initiative involving collaboration with other government agencies.

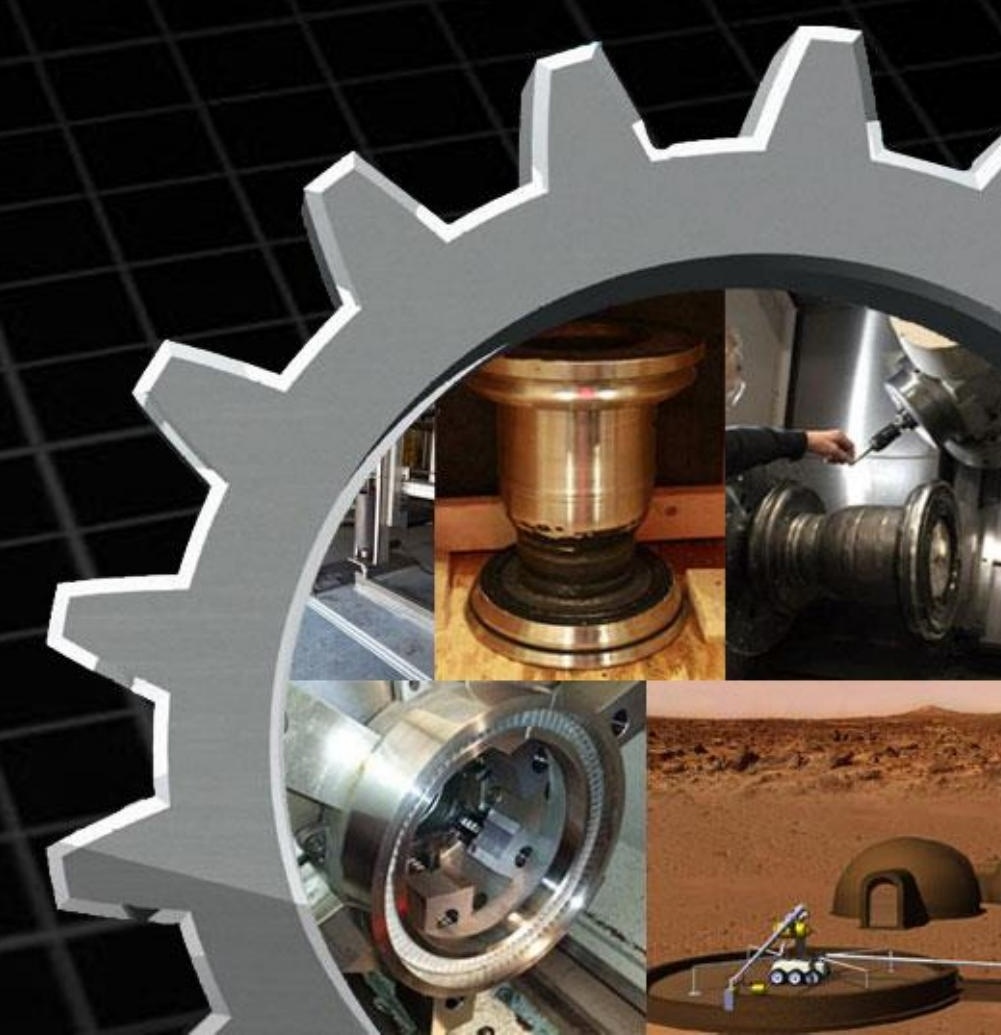




\section{Low Cost Upper Stage-Class Propulsion Development (LCUSP)}

Problem: The ability to produce innovative low cost upper stage-class propulsion systems using additive manufacturing technologies.

Technology/Solution: Utilize additive E-beam and SLM additive manufacturing techniques to produce a $25 \mathrm{~K}$-class hydrogen cooled propulsion chamber from GRCop and Inconel 625.

Innovation: This is a game changing technology that utilizes additive manufacturing to achieve cost and schedule savings by demonstrating critical material properties and performance.

Capability: A GRCop/Inconel 625 25K-class hydrogen cooled/regenerative propulsion chamber with a high thermal conductivity wall, structural capability and closed out printed channels.
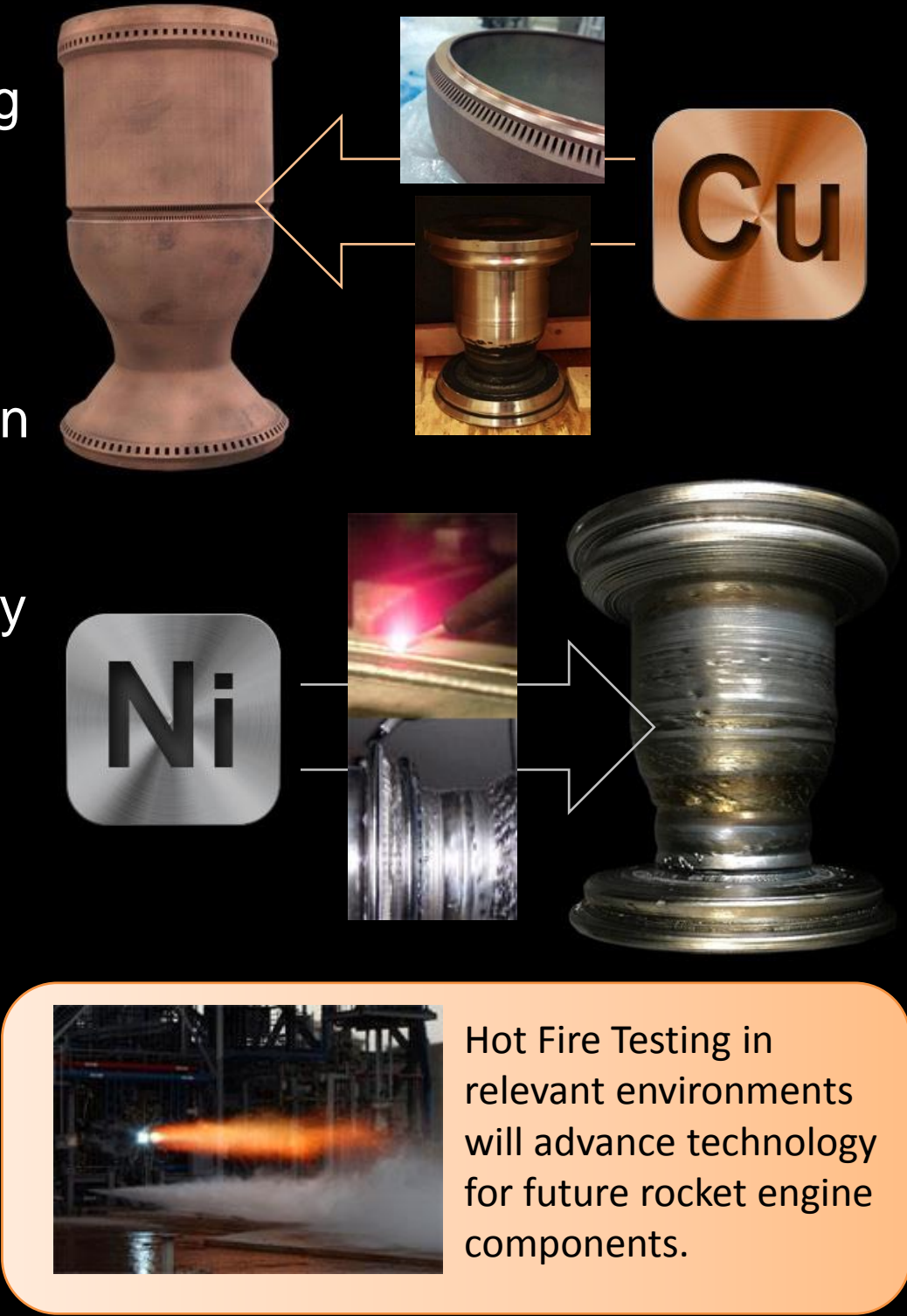


\section{Low Cost Upper Stage-Class Propulsion Partnerships}

$>$ Build foundational additive manufacturing industrial base by sharing engine chamber and nozzle material property data, relevant design data, and test data.

$>$ Future partnerships with commercial space industry could include materials development, additive manufacturing of engine components, machining techniques, sharing of test data and test infrastructure.

$>$ Both industry and NASA can benefit by reducing cost and schedule for new upper stage engines and enable new designs previously impossible with conventional fabrication methods.

$>$ NASA will continue to mature advanced manufacturing technologies by performing hot fire testing of the LCUSP additive manufactured chambers and nozzle, performing material property testing and building up the engine test infrastructure.
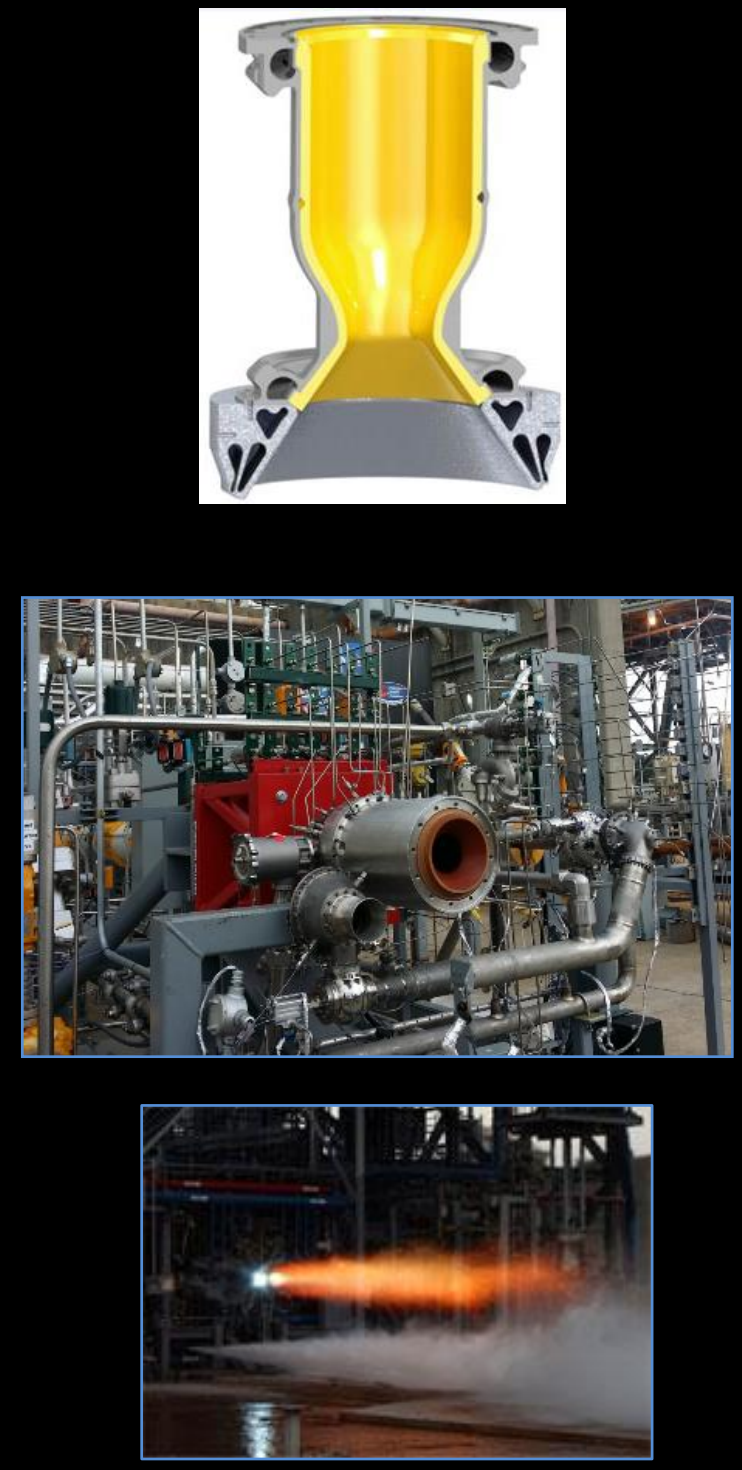


\section{Additive Manufacturing for Turbomachinery}

Problem: Reduce the cost and lead time for delivery of turbopump assemblies for upper stage propulsion systems.

Technology/Solution: Complete the build and assembly of one oxygen turbopump using additive manufacturing, demonstrate additive manufactured rotating and high pressure turbopump components in oxygen and infuse technology into the design process.

Innovation: This is a game changing technology that demonstrates critical oxygen turbopump hardware can be additively manufactured, integrated into a turbopump assembly, and successfully tested in liquid oxygen.

Capability: A demonstrated turbopump that can be incorporated into the Additive Manufacturing Demonstrator Engine (AMDE) for engine hot-fire testing or used for future LOX/Methane demonstrator encinec
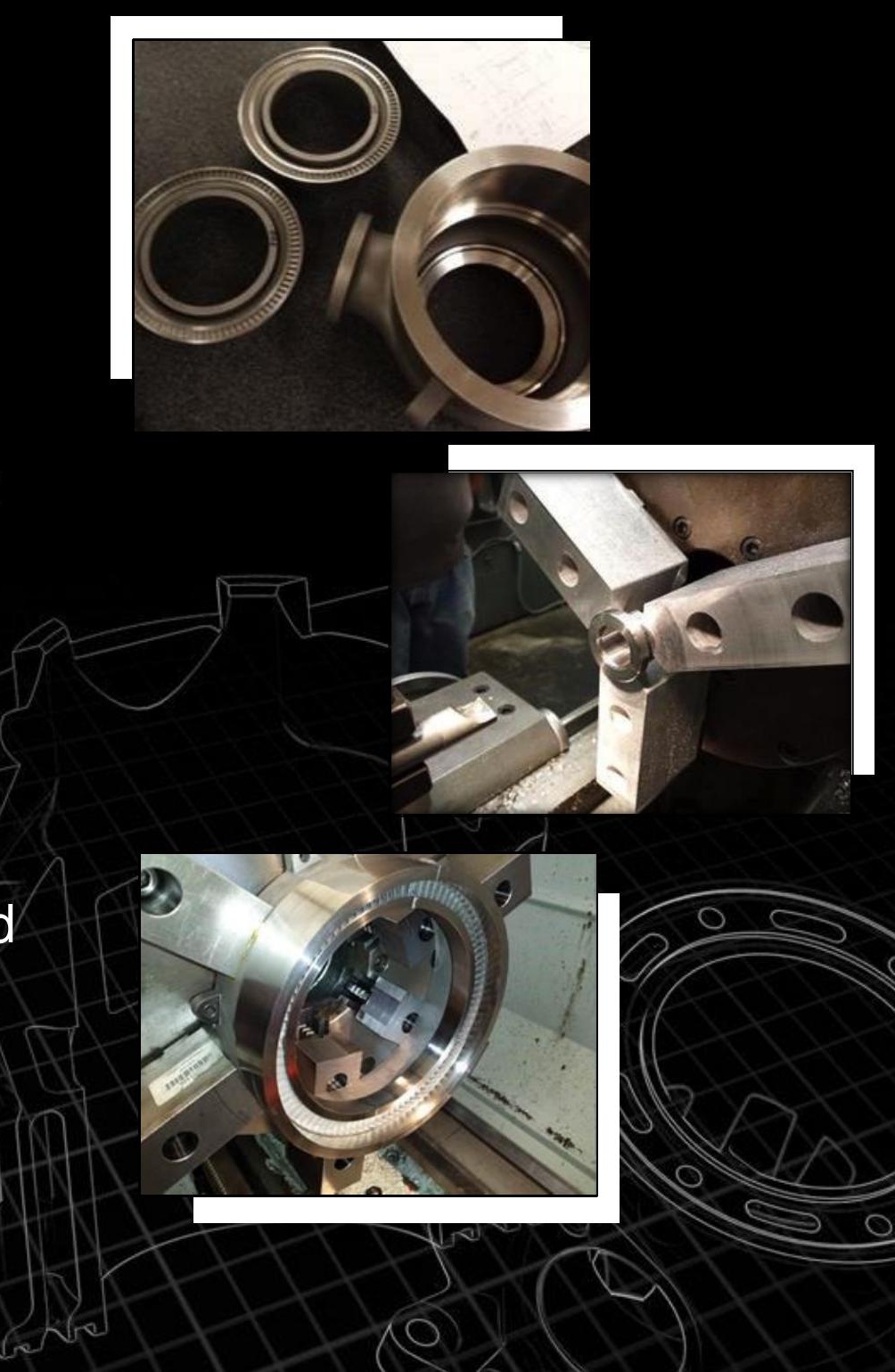


\section{Additive Manufacturing for Turbomachinery Partnerships}

$>$ Build foundational additive manufacturing industrial base by working through the builds of complex additive manufacturing turbopump part geometries with outside vendors to increase their build capabilities and confidence.

- Share lean and aggressive development philosophy.

- Share test data for turbomachinery operating in liquid oxygen.

$>$ Future partnerships with commercial space industry could include materials development, additive laser sinter melting manufacturing of engine components, post build machining techniques, and sharing of test data and test infrastructure.

$>$ Both industry and NASA benefit by reducing cost and lead time for turbomachinery. This applies to all future liquid propulsion systems including upper stage and in-space engines.

NASA will continue to mature advanced manufacturing technologies by performing material property testing and hot fire testing of additive manufactured engine parts.
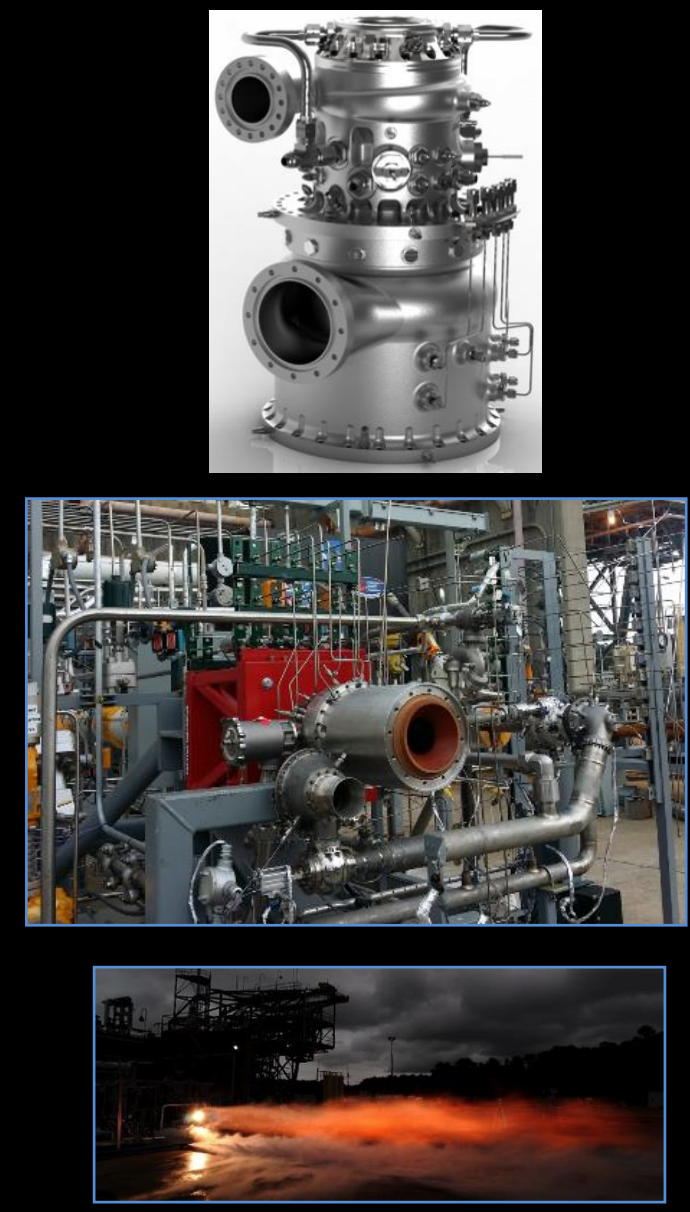


\section{Additive Construction with Mobile Emplacement (ACME)}

Problem: NASA currently lacks in-space construction capabilities to fabricate deep space mission infrastructure using in-situ materials.

Technology/Solution: Develop additive construction techniques and materials using known in-situ resources to enable human exploration missions.

Innovation: This is a game changing technology that develops capability to utilize in situ resources to fabricate planetary surface infrastructure, including habitats, garages, roads, and berms, with minimal mass launched from Earth:

Capab lity :Demonstrated additive construction capability with terrestrial and in-space applications.
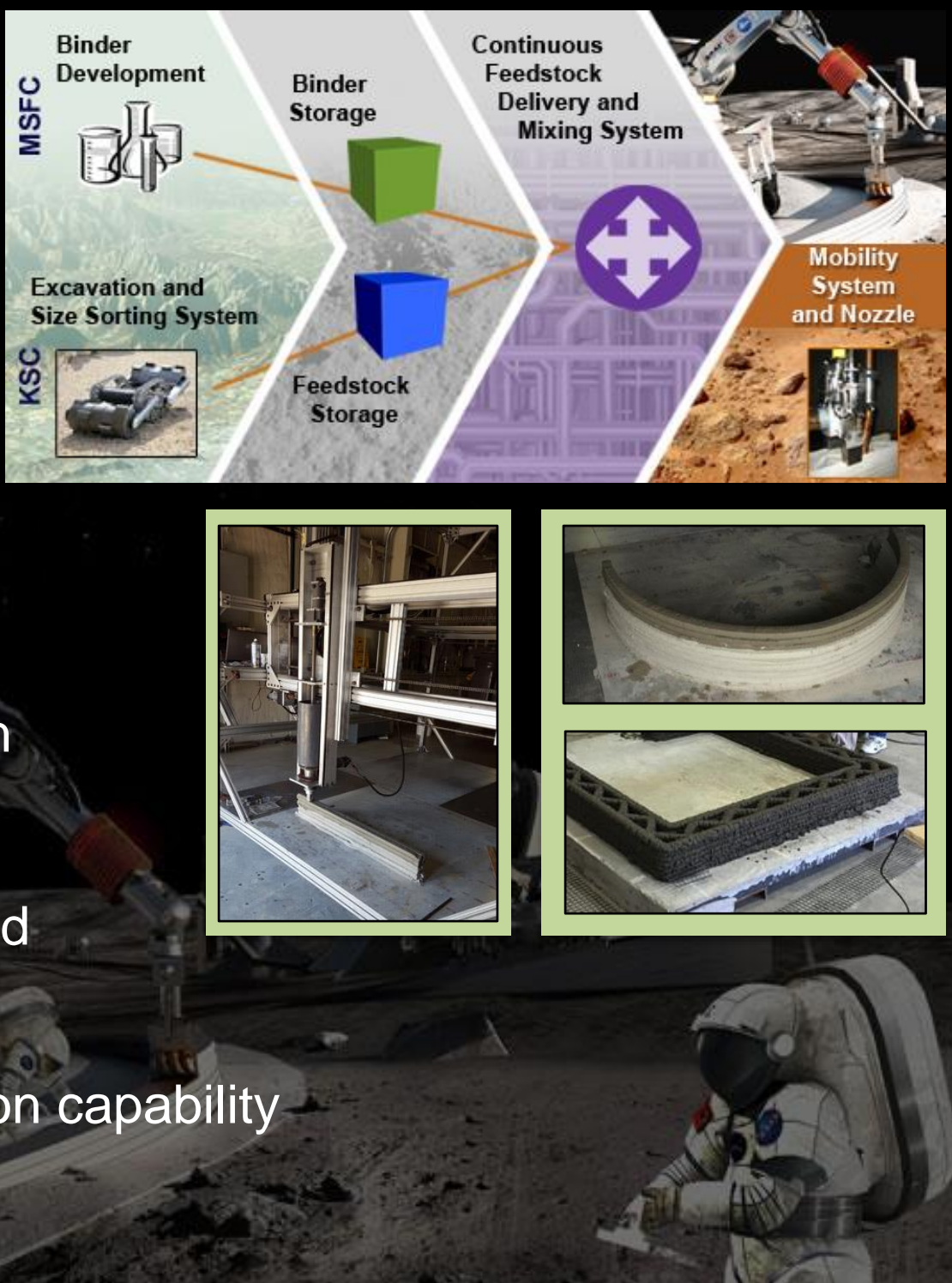


\section{ACME Partnerships}

$>$ NASA and the United States Army Corps of Engineers are jointly investing in additive construction technologies.

$>$ NASA is holding a new $\$ 2.25$ million competition to design and build a 3-D printed habitat for deep space exploration, including the agency's journey to Mars.

$>$ NASA is working with Contour Crafting Corporation, a small

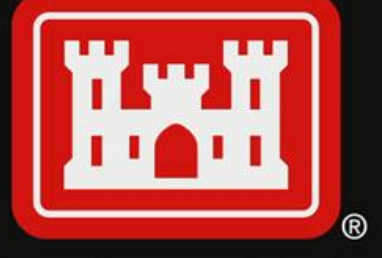

US Army Corps of Engineers

BUILDING STRONG ${ }_{\circledast}$ business that owns the Intellectual Property to an additive construction technique.

$>$ A Non Reimbursable Space Act Agreement is in work with Caterpillar, Inc.

$>$ Future partnerships with industry could include additive construction, materials development, and sharing of data.

$>$ Both industry and NASA benefit by reducing cost and schedule to enable future exploration missions by reducing launch mass requirements, improving space infrastructure affordability and applying technology to terrestrial needs.

$>$ NASA will continue to mature advanced manufacturing technologies by performing material property testing and building a representative structure to demonstrate additive construction. 


\section{Contact Information}

For more information about this technology or to discuss potential collaboration efforts:

John Fikes

john.fikes@nasa.gov

256-544-5570 